\title{
The Superior Role of Agricultural Growth in Reducing Child Stunting: An Instrumental Variables Approach
}

\author{
Sébastien Mary and Kelsey Shaw
}

\begin{abstract}
This chapter examines the impacts of agricultural growth and nonagricultural growth on the prevalence of child stunting in developing countries between 1984 and 2014. We find that a 10\% increase in agricultural gross domestic product (GDP) per capita would reduce stunting by $2.9 \%$, whereas a similar relative increase in non-agricultural GDP per capita would reduce stunting by only $2.2 \%$. We confirm that agricultural growth is superior to non-agricultural growth in reducing child stunting. However, given the moderate amplitude of the estimated effects, it is unlikely that a pro-poor growth strategy, even one focussed on agriculture, would generate sufficient stunting reductions in line with the Sustainable Development Goals (SDGs). Policymakers may consider prioritising their efforts towards complementary direct nutritional investments. We also estimate the reverse causal impacts of stunting on sectoral growth. Stunting costs on average approximately $13.6 \%$ of potential non-agricultural GDP per capita and $3.4 \%$ of potential agricultural GDP per capita.
\end{abstract}

\section{Introduction}

A majority of the literature has focussed on the impacts of aggregate economic growth on child stunting. While the amplitude of the aggregate impacts continues to be a topic of debate (e.g. Heltberg 2009; Ruel et al. 2013; Harttgen et al. 2013; Headey 2013; Vollmer et al. 2014; Alderman et al. 2014; Smith and Haddad 2015; O'Connell and Smith 2016), the literature has failed to address a more fundamental and practical question; that is, whether agricultural growth is more effective at reducing stunting

\footnotetext{
S. Mary ( $)$

Department of Economics, Driehaus College of Business, DePaul University, Chicago, USA

e-mail: smary@depaul.edu

K. Shaw

Coherent Economics, Chicago 60602, USA

e-mail: kelsey.shaw@coherentecon.com
} 
than non-agricultural growth. This chapter aims to answer this question while also addressing the central role of agriculture in pro-poor growth strategies in reducing hunger.

Agricultural growth has been considered more effective than non-agricultural growth in reducing undernutrition, because of the existence of large multiplier effects and intersectoral linkages that result in higher labour demand and higher wages in rural areas, allowing households to consume more calories and diversify their diets (Johnston and Mellor 1961; World Bank 2007; FAO et al. 2012). The supposedly superior role of agricultural growth also relies on the fact that many poor households and children affected by stunting live in rural areas. If economic growth emanates from agriculture more so than other sectors, greater participation by poor people in agriculture could produce a much greater benefit to rural households, and as a result to children (Mellor 1976). There are, however, a few mediating factors-such as market concentration, output tradability or overuse of fertilisers-that could limit the ability of agricultural growth to reduce undernutrition (e.g. Collier and Dercon 2009; World Bank 2007; Brainerd and Menon 2014).

Few studies have analysed the impacts of sectoral growth on child stunting. For example, Webb and Block (2012) find that stunting responds substantially to agricultural growth, but less so to non-agricultural growth. Using a sample of 29 countries, they claim that growth originating from agriculture may be at least twice as effective as growth emanating from non-agriculture. Headey (2013) finds that while nonagricultural growth reduces child stunting, agricultural growth is found to have no (statistically significant) impact on child stunting. Additionally, he finds that the difference between the estimated impacts of agricultural and non-agricultural growths is not statistically significant. On the contrary, Mary et al. (2018a, b) find that the estimated impacts are relatively large, in that a $10 \%$ increase in agricultural (nonagricultural) GDP per capita reduces child stunting by $9.6 \%(8.4 \%)$, concluding that agricultural growth is superior to non-agricultural growth for generating child stunting reductions. Given the lack of consensus and research, whether agricultural growth is superior for reducing child stunting remains an open question.

Previous studies in the literature have also often ignored the existence of reverse causality between economic growth and stunting. Not only does growth affect stunting, but stunting may affect growth. This is important to consider, because ordinary least squares (OLS) estimates are biased downward, since the reverse causality is presumably negative, and therefore the impact of economic growth is overstated. Yet, some studies have attempted to account for the reverse causality. For instance, Webb and Block (2012) account for the endogeneity bias by using generalised method of moments (GMM) estimations. However, such estimators have been heavily criticised for their lack of reliability (Bazzi and Clemens 2013). Mary et al. (2018a, b) use a natural experiment based on temperature variations, but their approach relies on a strong identifying assumption: that temperature shocks have no physiological effects on child nutrition. Other studies have used instrumental variables, using cereal yields or investment rates as instruments (Vollmer et al. 2014; Smith and Haddad 2015), but the latter may not be plausibly exogenous instruments (Mary et al. 2018a, b; Mary 2018). 
Instead, this chapter uses a novel approach to accounting for the reverse causal effect of stunting on agricultural and non-agricultural growths. The estimation strategy identifies the causal impact of agricultural and non-agricultural per capita GDPs (in logs) on stunting, by extending a two-step procedure that has been used in comparable contexts where the search for valid instruments has been especially elusive (e.g. Brückner 2013; Brückner and Lederman 2015). First, we estimate the reverse causal impacts of child stunting on both agricultural and non-agricultural per capita GDPs, using rainfall and temperature anomalies as instrumental variables (IVs) to generate exogenous variations in child stunting. In a second step, we estimate the effect that agricultural and non-agricultural growths have on stunting, using the residual agricultural and non-agricultural per capita GDPs that are not driven by stunting as an instrument. Not only does the approach estimate the impact of sectoral growth on stunting, it also estimates the reverse causal impacts of stunting on sectoral growth.

Using a dataset of 69 developing countries, between 1984 and 2014, we find that a $10 \%$ increase in agricultural (non-agricultural) GDP per capita would reduce stunting prevalence by $2.9 \%(2.2 \%)$. The impacts of agricultural growth are higher than the impacts of non-agricultural growth, but remain relatively modest. Still, we find statistical support that agricultural growth is more effective than non-agricultural growth. However, given the moderate amplitude of the estimated effects, it is unlikely that a pro-poor growth strategy, even focussed on agriculture, would generate sufficient stunting reductions in line with the SDGs. We also estimate the reverse causal impacts of stunting on current growth and find that a $1 \%$ point increase in stunting prevalence results in a $0.1 \%(0.4 \%)$ decrease in agricultural (non-agricultural) GDP per capita. A back-of-the-envelope calculation suggests that stunting costs approximately $13.6 \%$ of potential non-agricultural GDP per capita and $3.4 \%$ of potential agricultural GDP per capita. The remainder of the chapter is as follows. Section 2 describes the empirical model and the identification strategy. Section 3 presents the dataset. Section 4 analyses the results. Section 5 concludes.

\section{Model and Identification Strategy}

There are several conceptual frameworks that identify and distinguish causal factors to help comprehend undernutrition. For example, the UNICEF model (1998) classifies the determinants of nutrition into three categories: immediate, underlying and basic. This classification has often provided a theoretical background for modelling stunting, and most empirical studies have typically focussed on one category. The scope of this chapter covers the most structural factors, or basic determinants, with a focus on sectoral economic growth. In line with most studies in the literature, we do not include control variables from a different group of causal factors. 


\subsection{Empirical Model}

The model can be expressed as follows:

$$
y_{i t}=\alpha x_{i t}^{\mathrm{AG}}+\beta x_{i t}^{\mathrm{NONAG}}+\gamma z_{i t}+c_{i}+d_{t}+\varepsilon_{i t}
$$

where country is indexed by $i$ and year is indexed by $t ; y_{i t}$ is the prevalence of child stunting of country $i$ in year $t ; x_{i t}^{\mathrm{AG}}$ is the weighted logarithm of agricultural GDP per capita; $x_{i t}^{\text {NONAG }}$ is the weighted logarithm of non-agricultural GDP per capita; $z_{i t}$ is a vector of independent variables, including a composite index of governance and urbanisation. $c_{i}$ is a country-specific effect. $d_{t}$ represents time dummies. The inclusion of country and period fixed effects accounts for the presence of timeinvariant omitted variables and common shocks affecting both stunting and sectoral growth, respectively.

Separating GDP into sectoral components allows us to investigate their relative roles in reducing stunting. Following the existing literature, each sector's logged GDP is weighted by its share in total GDP, to account for the size of each sector at the country level. This accounts for the fact that the impact of a given increase in agricultural GDP per capita, or agricultural growth, is likely to be small (large) in a country with a small (large) agricultural sector such as Chile (Cameroon). Also, the introduction of sectoral weights implicitly accounts for the country's (more or less advanced) stage of development.

In line with the existing literature, we include several other independent variables, namely urbanisation and governance. ${ }^{1}$ The inclusion of these variables is guided by the desire to avoid the loss of stunting observations, as well as to follow the existing literature (e.g. Smith and Haddad 2015; Mary et al. 2018a, b). We also test a more extended version of this model in robustness analyses.

Given our focus on nutrition, we follow Smith and Haddad (2015) and define governance as the set of traditions, policies and institutions (and implicitly their effectiveness) that work towards ensuring food security, especially for children. For example, more democratic governments are more likely to ensure that the benefits of higher national income reach those who need it the most, by spending a higher share of their revenues on social and nutrition-relevant infrastructures. Also, the urbanisation rate controls for the increasing migration of populations towards urban areas in many developing countries, where the provision of nutrition and social services is of higher quality and likely more stable.

Mary et al. (2018a, b) argue that a stunting prevalence observation in a specific year, for example 2000, is affected by factors determined as early as 1995, and recommend using a model where regressors are replaced by their five-year moving averages. Equation (1) can therefore be rewritten as:

$$
y_{i t}=\delta x_{i t}^{\mathrm{AG}-\mathrm{MA} 5}+\theta x_{i t}^{\mathrm{NONAG}-\mathrm{MA} 5}+\vartheta z_{i t}^{M A 5}+f_{i}+g_{t}+{ }_{i t}
$$

\footnotetext{
${ }^{1}$ Most studies in the aggregate literature typically include one or no additional independent variables.
} 
where the superscript MA5 denotes the five-year rolling average of the regressor. For example, the five-year moving average of agricultural growth is calculated as follows:

$$
x_{i t}^{\mathrm{AG}-\mathrm{MA} 5}=\frac{\left(x_{i t}^{\mathrm{AG}}+x_{i t-1}^{\mathrm{AG}}+x_{i t-2}^{\mathrm{AG}}+x_{i t-3}^{\mathrm{AG}}+x_{i t-4}^{\mathrm{AG}}\right)}{5}
$$

\subsection{Estimation}

As explained in the introduction, finding a strategy to account for reverse causality can be challenging. In this chapter, we extend the two-step approach devised by Brückner (2013). As a first step, we estimate the effect that stunting has on both agricultural and non-agricultural per capita GDPs, using an instrumental variable (IV) approach. ${ }^{2}$ Equations (3) and (4) present the first-step estimations ${ }^{3}$ :

$$
\begin{gathered}
x_{i t}^{\mathrm{AG}-\mathrm{MA5}}=\pi y_{i t}+\rho x_{i t}^{\mathrm{NONAG-MA5}}+\sigma z_{i t}^{\mathrm{MA5}}+h_{i}+r_{t}+\tau_{i t} \\
x_{i t}^{\text {(NONAG-MA5) }}=\varphi y_{i} t+\omega x_{i} t^{\text {(AG-MA5) }}+\zeta z_{i} t^{M} A 5+j_{i}+k_{t}+\xi_{i t}
\end{gathered}
$$

The statistical significance of $\pi$ and $\varphi$ provides direct endogeneity tests of stunting to agricultural and non-agricultural growths, respectively. Estimating the effect that stunting has on agricultural and non-agricultural GDP per capita requires an exogenous source of variation for stunting. Therefore, rainfall and temperature anomalies, defined here as deviations from the long-run mean calculated over the full sample period-and higher moments - are used as excluded instruments in the two-stage least squares (2SLS) estimation of Eq. (2). Weather anomalies $(z)$ are generally defined as follows:

$$
z_{i t}=\frac{a_{i t}-\overline{a_{i}}}{\overline{a_{i}}}
$$

where $\overline{a_{i}}$ is the mean temperature (rainfall) level, observed over the full-time period, in country $i ; a_{i t}$ is the temperature (rainfall) level in year $t$. If $z_{i t}$ is positive (negative), this indicates that the average temperature (rainfall) in year $t$ in country $i$ is above (below) the long-run level. Higher moments of $z$ capture potentially nonlinear effects.

Then, in a second step, if we construct adjusted per capita sectoral GDP series, where the responses of per capita agricultural and non-agricultural GDP to stunting have been 'partialled out' using estimates from Eqs. (3) and (4):

\footnotetext{
${ }^{2}$ We thank Markus Bruckner for the suggestion on how to extend his approach to two endogenous variables.

${ }^{3} \mathrm{We}$ also account for intersectoral linkages by considering non-agricultural GDP per capita endogenous in Eq. (3) and agricultural GDP per capita endogenous in Eq. (4).
} 


$$
\begin{gathered}
x_{i t}^{\mathrm{AG} *}=x_{i t}^{\mathrm{AG}-\mathrm{MA} 5}-\pi y_{i t}-\rho x_{i t}^{\mathrm{NONAG}-\mathrm{MA} 5}-\sigma z_{i t}^{\mathrm{MA} 5} \\
x_{i t}^{\mathrm{NONAG} *}=x_{i t}^{\mathrm{NONAG}-\mathrm{MA} 5}-\varphi y_{i t}-\omega x_{i t}^{\mathrm{AG}-\mathrm{MA} 5}-\zeta z_{i t}^{\mathrm{MA} 5}
\end{gathered}
$$

$x_{i t}^{\mathrm{AG} *}$ and $x_{i t}^{\mathrm{NONAG} *}$ are free of the endogeneity bias and are, respectively, used to instrument $x_{i t}^{\text {AG-MA5 }}$ and $x_{i t}^{\text {NONAG-MA5 }}$ in estimating Eq. (2) via 2 SLS. The secondstep estimation is exactly identified. Instruments are also included as independent variables in the second-step estimation. Other independent variables are assumed exogenous.

\subsection{Identification}

What makes this identification strategy plausible? First, temperature or rainfall anomalies are, by definition, exogenous and random. Second, weather shocks affect the physiology of children and are therefore likely correlated with stunting prevalence (Millward 2017). Third, stunting is not fully determined within the first two years of a life, and as such is not a static phenomenon. Stunting has been portrayed as a chronic condition because of growth faltering (i.e. height-for-age of children observed later in life is, to some degree, a reflection of failure to grow before age 2). However, there is an intense ongoing debate as to whether substantial height catchup can occur between 24 months and mid-childhood, even in the absence of any interventions (Prentice et al. 2013a, b; Prendergast and Humphrey 2014; Leroy et al. 2013). In a seminal paper, Prentice et al. (2013a, b) show that a pubertal growth phase in rural Gambian children allows very considerable height recovery and conclude that their data are sufficient to dispel the myth of life-long size entrainment by age 24 months (Prentice et al. 2013b).

The main assumption for our identification strategy is that current weather anomalies are physiological shocks that affect stunting, and hence sectoral GDP per capita. Given the high incidence of child labour in developing countries, ${ }^{4}$ it is expected that the impacts will affect both agricultural and non-agricultural sectors, though it is not clear what type of growth will suffer most from the burden of child undernutrition.

What about the exclusion restriction for the estimation of Eqs. (3) and (4)? Given the modelling framework, the exclusion restrictions are valid by design. Indeed, it would be impossible for current weather anomalies to affect variables that now mainly represent previous sectoral growth. Additionally, the Hansen J-test for overidentification of all instruments is used to investigate the validity of our instruments. This tests the null hypothesis that the instruments are uncorrelated with the error term. If the $p$-value is below $10 \%$, we can conclude that all instruments are not exogenous and therefore invalid. The strength of instruments is further examined by reporting the Kleibergen-Paap rk Wald $F$ statistic (or $F$-statistic), which we compare with the

\footnotetext{
${ }^{4}$ It is estimated that more than one in five children in Africa are employed against their will in stone quarries, farms and mines (ILO 2017).
} 
critical values from Stock and Yogo (2005) for testing weak instruments. We test the null hypothesis that the maximum relative bias and size distortions are greater than 10,15 or $20 \%$.

\section{Data}

In this study, we initially collect a dataset on child stunting and several basic determinants, for a sample of 86 low-income and middle-income countries between 1984 and 2014. Given that the impact of governance needs to be observed over the long run, the selection of countries and years is determined by available data on governance. The Political Risk Services (PRS) dataset from the International Country Risk Guide combines a large country coverage and long-time series on multiple dimensions of governance and has been used extensively in empirical research. We gather data for all low-income and middle-income countries and for the years available in the PRS dataset. We then exclude countries with less than two observations on child stunting over the period. We find no outlier using the Hadi procedure (based on 5\% level). The final sample includes 69 countries for 369 observations.

In line with the most recent studies, we use stunting (height-for-age) as the dependent variable, rather than wasting or underweight (weight-for-age). In doing so, we acknowledge that stunting has become a reference variable because it better captures the process of undernutrition in the medium run.

Data for the prevalence of stunted children under age 5 are taken from the World Health Organization (WHO). Such data have been used in previous studies (Ruel et al. 2013; Smith and Haddad 2015; Mary et al. 2018a, b) and have the primary advantage of possessing a larger country coverage than the Demographic and Health Surveys. The prevalence of stunting is the percentage of children under age 5 whose heightfor-age is more than two standard deviations below the median for the international reference population aged 0-59 months. For children up to 2 years old, height is measured by recumbent length. For older children, height is measured by stature while standing. The data is based on the child growth standards released in 2006 by the WHO. While there are other stunting variables that cover partial life range (2436 months), most studies use the 0-59 months reference. Therefore, our decision to use this measure is driven by the need for comparison with existing studies. This measure has also often been used in policy discussions and has attracted much attention across all development stakeholders. It is also now directly recognised in the SDG agenda (SDG 2, Target 2.2).

For agricultural growth and non-agricultural growth, we use data from the World Bank database. GDP per capita is GDP divided by mid-year population. GDP is the sum of gross value added by all resident producers in the economy, plus any product taxes and minus any subsidies not included in the value of the products. Data are in constant USD 2011 (in purchasing power parity). The decomposition of GDP is based on the calculation of each sector's GDP (per capita) and the size of each sector 
within the economy; it is based on the industrial origin of value added, from the International Standard Industrial Classification (ISIC), Revision 3.

The PRS dataset provides 12 indicators, based on expert analyses, covering both political and social attributes to capture governance in its different characteristics. We use an index of governance similar to the one used in Smith and Haddad (2015), combining: (1) Bureaucratic Quality-the institutional strength and quality of the bureaucracy; (2) Law and Order-the strength and impartiality of the legal system and popular observance of the law; (3) Government Stability-the government's ability to carry out its declared programme and associated policies, and its ability to stay in office; (4) Corruption within the political system-a threat to foreign investment by distorting the economic and financial environment, reducing the efficiency of government and business by enabling people to assume positions of power through patronage rather than ability, and introducing inherent instability into the political process; and (5) Democratic Accountability-a measure of how responsive government is to its people, on the basis that the less responsive it is, the more likely it is that the government will fall-peacefully in a democratic society, but potentially violently in a non-democratic one (PRS 2016).

The index is the simple mean of these five indicators for each country-year data point, after placing each on a 0-1 scale to establish equivalent ranges and weights. Each dimension of governance, as shown above, can directly or indirectly promote reductions in child stunting. For example, bureaucratic effectiveness and political stability directly contribute to the quality and reliability of the provision of nutrition and social services that support many children's nutritional status. Similarly, democratic accountability ensures that pressures are maintained for public action because increased awareness of the issue of nutrition is likely to make governments more responsive to the needs of food insecure people, especially children.

Other variables are taken from the World Development Indicators (WDIs). Temperature data are from the Climate Research Unit (CRU) and the Tyndall Centre for Climate Change Research (TYN) of the University of East Anglia. Table 3 in Appendix displays descriptive statistics.

\section{Results}

This chapter examines whether agricultural and non-agricultural growths reduce the prevalence of child stunting. Constant terms are included in the estimations. We use country-clustered standard errors that are robust to heteroscedasticity.

\subsection{Effect of Child Stunting on Sectoral Growth}

Table 1 displays the estimates for the effect that stunting has on agricultural growth in column 2, and on non-agricultural growth in column 4 . The associated first-stage 
Table 1 Effect of child stunting prevalence on sectoral growth

\begin{tabular}{|c|c|c|c|c|}
\hline \multirow[t]{3}{*}{ Dependent variable } & First stage & 2SLS-IV & First stage & 2SLS-IV \\
\hline & (1) & (2) & (3) & (4) \\
\hline & Stunting & AG growth & Stunting & NAG growth \\
\hline \multirow[t]{2}{*}{ Child stunting prevalence } & & $-0.001 * * *$ & & $-0.004 * * *$ \\
\hline & & {$[0.00]$} & & {$[0.00]$} \\
\hline \multirow[t]{2}{*}{ Urbanisation } & & $0.016 \#$ & & 0.024 \\
\hline & & $(1.52)$ & & $(1.37)$ \\
\hline \multirow[t]{2}{*}{ Governance index } & & 0.006 & & 0.122 \\
\hline & & $(0.03)$ & & $(0.44)$ \\
\hline \multirow[t]{2}{*}{ Rainfall anomaly } & -2.527 & & -2.527 & \\
\hline & $(-1.33)$ & & $(-1.33)$ & \\
\hline \multirow[t]{2}{*}{ Temperature anomaly } & $-2.443 * * *$ & & $-2.443 * * *$ & \\
\hline & $(-5.71)$ & & $(-5.71)$ & \\
\hline \multirow[t]{2}{*}{ Temperature anomaly, squared } & $0.142 * *$ & & $0.142 * *$ & \\
\hline & $(2.14)$ & & $(2.14)$ & \\
\hline \multirow[t]{2}{*}{ Temperature anomaly, cubic } & $0.083 * * *$ & & $0.083 * * *$ & \\
\hline & $(5.41)$ & & $(5.41)$ & \\
\hline Observations & 369 & 369 & 369 & 369 \\
\hline Number of countries & 69 & 69 & 69 & 69 \\
\hline Country fixed effects & Yes & Yes & Yes & Yes \\
\hline Year fixed effects & Yes & Yes & Yes & Yes \\
\hline Hansen $\mathrm{J}, p$-value & n.a. & 0.43 & n.a. & 0.38 \\
\hline First-stage $F$-stat & n.a. & 11.01 & n.a. & 15.74 \\
\hline Stock-Yogo $10 \%$ size & n.a. & 16.87 & n.a. & 16.87 \\
\hline Stock-Yogo $20 \%$ size & n.a. & 7.54 & n.a. & 7.54 \\
\hline Stock-Yogo $10 \%$ relative bias & n.a. & 7.56 & n.a. & 7.56 \\
\hline Stock-Yogo $20 \%$ relative bias & n.a. & 5.57 & n.a. & 5.57 \\
\hline
\end{tabular}

Source Authors' calculations

$A G$ agricultural; $N A G$ non-agricultural

Notes $*, * *, * * *$ : significant at $10 \%, 5 \%, 1 \%{ }^{\#}$ : marginally insignificant $(p<0.15)$. $t$-statistics in parentheses. Each sector's growth is weighted by the sector's share of value added in total GDP

estimates that link rainfall and temperature anomalies to stunting are respectively displayed in columns 1 and 3. Increased rainfalls from their long-run levels are associated with decreased stunting, while temperature anomalies have various effects depending on the size of the anomaly. In other words, small-scale (large-scale) positive temperature anomalies decrease (increase) stunting.

The 2SLS estimate in column 2 of Table 1 suggests that a percentage point increase in child stunting prevalence decreases agricultural GDP per capita by $0.1 \%$. A similar increase in child stunting would also decrease non-agricultural GDP per capita 
by $0.4 \%$ according to the estimate in column 4 . A quick calculation based on the estimates in columns 2 and 4 suggests that, on average, stunting costs developing countries about $13.6 \%$ of potential non-agricultural GDP per capita and $3.4 \%$ of potential agricultural GDP per capita.

More fundamentally, the existence of negative reverse causal effects implies that OLS estimates of the impact of sectoral growth on stunting would be biased downwards. For both estimations in columns 2 and 4, the @@F-statistics suggest that weak instruments are not a problem as they are well above the $20 \%$ Stock-Yogo critical values. The $p$-values associated with the Hansen J-test are greater than $10 \%$ in columns 2 and 4, indicating that the tests do not reject that the instruments are uncorrelated with the second-stage error.

\subsection{Effect of Sectoral Growth on Child Stunting}

Table 2 shows the estimates of the effect of both agricultural and non-agricultural growths on stunting. The 2SLS coefficients are also higher than their OLS counterparts, in line with the existence of negative reverse causality. More importantly, the 2SLS coefficients (using the residuals calculated on the estimates in columns 2 and 4 in Table 1) are negative, significant at $1 \%$ in column 2 , and imply that a $10 \%$ increase in agricultural (non-agricultural) GDP per capita would reduce stunting prevalence by $2.9 \%{ }^{5}(2.2 \%)$.

These findings are partially in line with Webb and Block (2012), who use a semiparametric regression. However, we do not find supporting evidence that agricultural growth is twice as effective as non-agricultural growth, perhaps because we use a much larger dataset. Also, our results pertaining to the role of agricultural growth seem to be in contrast with Headey (2013). Despite this, the latter combines disaggregated state data for India (rather than country-level data) as well as country data in his dataset. Therefore, some caution must be applied when comparing our results with this study. Further, we find impacts that are much lower than in Mary et al. (2018a, b).

Furthermore, the 2SLS coefficient for agricultural growth is larger than for nonagricultural growth, suggesting the relative superiority of agricultural growth in the fight against children's food insecurity. A Wald test shows that the difference between agricultural growth and non-agricultural growth effects is indeed statistically significant, though at a $10 \%$ level ( $p$-value: 0.05 ). That is, we find statistically significant support that agricultural growth is superior to non-agricultural growth towards reducing the number of stunted children in developing countries.

This result seems to be in contrast with Headey (2013), who finds no supporting evidence that the structure of growth matters for stunting reductions, but in line with Mary et al. (2018a, b). Also, we note that the OLS estimates in column 1 of Table 2 imply that the sectoral composition of growth does not affect child stunting

${ }^{5}$ This is calculated as: $\frac{9.848}{33.87} * \frac{10}{100} \approx 2.9 \%$. 
Table 2 Effect of sectoral growth on child stunting

\begin{tabular}{|c|c|c|}
\hline \multirow[t]{2}{*}{ Child stunting prevalence } & OLS-FE & 2SLS-IV \\
\hline & (1) & (2) \\
\hline \multirow[t]{2}{*}{ Agricultural growth } & $-10.249 * * *$ & $-9.848 * * *$ \\
\hline & $(-3.40)$ & $(-3.77)$ \\
\hline \multirow[t]{2}{*}{ Non-agricultural growth } & $-10.790 * * *$ & $-7.312 * * *$ \\
\hline & $(-4.64)$ & $(-3.26)$ \\
\hline \multirow[t]{2}{*}{ Urbanisation rate } & $-0.472 * * *$ & $-0.343^{* *}$ \\
\hline & $(-4.03)$ & $(-2.16)$ \\
\hline \multirow[t]{2}{*}{ Governance index } & $-17.982 * * *$ & $-20.489 * * *$ \\
\hline & $(-3.33)$ & $(-2.59)$ \\
\hline \multirow[t]{2}{*}{ Rainfall anomaly } & & $-2.874 \#$ \\
\hline & & $(-1.63)$ \\
\hline \multirow[t]{2}{*}{ Temperature anomaly } & & $-1.999 * * *$ \\
\hline & & $(-4.61)$ \\
\hline \multirow[t]{2}{*}{ Temperature anomaly, squared } & & $0.104 *$ \\
\hline & & $(1.71)$ \\
\hline \multirow[t]{2}{*}{ Temperature anomaly, cubic } & & $0.071 * * *$ \\
\hline & & $(4.14)$ \\
\hline Observations & 369 & 369 \\
\hline Number of countries & 69 & 69 \\
\hline Country fixed effects & Yes & Yes \\
\hline Year fixed effects & Yes & Yes \\
\hline Ramsey RESET test & 0.04 & 0.13 \\
\hline First-stage $F$-stat & n.a. & 648.9 \\
\hline H0: AG > Non-AG, $p$-value & 0.64 & 0.05 \\
\hline
\end{tabular}

Source Authors' calculations

Notes *, **, ***: significant at $10 \%, 5 \%, 1 \%$. \#: marginally insignificant $(p<0.15)$. $t$-statistics in parentheses. Each sector's growth is weighted by the sector's share of value added in total GDP. RESET tests are based on GMM distance

reductions. This may suggest that ignoring endogeneity may lead to wrong policy implications with respect to the relative importance of agricultural growth towards reducing child nutrition.

Lastly, we find that governance reduces stunting. Our estimate is negative, significant at $1 \%$ but somewhat higher than the estimate found in Smith and Haddad (2015). This suggests that governance plays a key role in food security. The coefficient for the urbanisation rate is also negative and significant at 5\%. The Kleibergen-Paap statistic is well above the Stock-Yogo critical values and suggests that weak instruments are not a problem. Finally, the RESET test seems to indicate that an appropriate form has been used ( $p$-value: 0.13 ), and omitted variable bias is likely not a problem. 


\subsection{Robustness Analyses}

We investigate the robustness of our empirical results to the: (1) exclusion of year dummies; (2) use of data for sub-Saharan Africa (SSA) and Asia only (where the majority of stunted children live); (3) exclusion of Bangladesh, which is the country with the highest number of stunting observations in the sample; (4) use of a basic model; and (5) use of an extended model. The extended model includes trade openness (exports plus imports, divided by GDP), following Levine and Rothman (2006), and a measure of the military's involvement in politics from the PRS dataset. Trade may affect children's health through a number of pathways, including the degree to which governments are willing and able to fund public health, higher access to clean water, or health care (Levine and Rothman 2006). Military involvement may stem from an external or internal threat, be symptomatic of underlying difficulties, or be a full-scale military takeover. The military may also control food supply or use it as a weapon or payment for political support, therefore disrupting its distribution to the populations who need food the most.

Estimation tables can be found in Appendix Table 4. Our overall conclusion from these robustness tests is that the main pattern of results remains the same. We summarise the main results below:

(1) For all alternative specifications, excluding the one without year dummies, agricultural growth is statistically superior to non-agricultural growth in reducing child stunting (only marginally for the basic model).

(2) Focussing on SSA and Asia does not change our empirical results (column 2, Table 4).

(3) Dropping Bangladesh from our sample does not affect the empirical results (column 3, Table 4).

(4) Sectoral growth coefficients are much lower in the model without year dummies and the basic model (columns 1 and 4, Table 4).

(5) Non-agricultural growth is found to have no statistically significant impact on stunting in the basic model (column 4, Table 4).

(6) We find that trade openness decreases stunting, while a higher military presence in politics is associated with higher stunting in the extended model (column 5, Table 4).

\section{Conclusions}

This chapter has estimated and compared the impacts of increases in agricultural and non-agricultural GDP per capita on the prevalence of child stunting. We find that both types of growth reduce stunting. In particular, our findings show that a $10 \%$ increase in agricultural (non-agricultural) GDP per capita reduces child stunting, on average, by $2.9 \%(2.2 \%)$. We further examine whether the sectoral composition 
of growth matters for stunting reductions and find evidence that growth emanating from agriculture is more effective at reducing stunting than non-agricultural growth. This provides support for the view that the agricultural sector is the most important sector for fighting undernutrition.

However, given the relatively moderate amplitude of the estimated effects, it is unlikely that a pro-poor growth strategy, even focussed on agriculture, would generate sufficient stunting reductions in line with the SDGs. While Dercon (2013) questions the putative superior role of agriculture in development, our results would seem to suggest that economic growth, whether it originates from agriculture or not, may not have enough oomph to generate large reductions in child stunting. In fact, given the available evidence on nutrition-specific and nutrition-sensitive investments (e.g. Bhutta et al. 2008; Mary et al. 2018a, b), policymakers should consider prioritising their efforts towards complementary direct nutritional investments.

Acknowledgements The authors thank Sergio Gomez y Paloma and Laura Riesgo for useful comments. Data and Stata codes are available upon request.

\section{Appendix}

See Tables 3 and 4.

Table 3 Descriptive statistics of sample

\begin{tabular}{l|l|l|l|l|l}
\hline \multirow{2}{*}{ Variables } & $(1)$ & $(2)$ & $(3)$ & $(4)$ & $(5)$ \\
\cline { 2 - 6 } & $N$ & Mean & Standard deviation & Min & Max \\
\hline Child stunting prevalence & 369 & 33.87 & 14.55 & 4.3 & 76.7 \\
\hline $\begin{array}{l}\text { Agricultural GDP per capita, } \\
\text { weighted log }\end{array}$ & 369 & 1.39 & 0.75 & 0.13 & 3.80 \\
\hline $\begin{array}{l}\text { Non-agricultural GDP per } \\
\text { capita, weighted log }\end{array}$ & 369 & 6.09 & 1.60 & 2.39 & 9.16 \\
\hline Governance index & 369 & 0.50 & 0.10 & 0.16 & 0.75 \\
\hline Urbanisation & 369 & 42.29 & 18.15 & 10.26 & 86.46 \\
\hline Trade openness & 369 & 64.61 & 32.39 & 13.04 & 222.25 \\
\hline Military in politics & 369 & 0.49 & 0.24 & 0 & 1 \\
\hline Rainfall anomaly & 369 & 0.005 & 0.13 & -0.50 & 0.46 \\
\hline Temperature anomaly & 369 & 0.011 & 0.59 & -6.93 & 4.93 \\
\hline
\end{tabular}


Table 4 The effect of sectoral growth on child stunting: robustness analyses

\begin{tabular}{|c|c|c|c|c|c|}
\hline \multirow{3}{*}{$\begin{array}{l}\text { Child stunting } \\
\text { prevalence }\end{array}$} & 2SLS-IV & 2SLS-IV & 2SLS-IV & 2SLS-IV & 2SLS-IV \\
\hline & (1) & (2) & (3) & (4) & (5) \\
\hline & $\begin{array}{l}\text { No year } \\
\text { dummies }\end{array}$ & $\begin{array}{l}\text { SSA and } \\
\text { SEA }\end{array}$ & $\begin{array}{l}\text { No } \\
\text { Bangladesh }\end{array}$ & $\begin{array}{l}\text { Basic } \\
\text { model }\end{array}$ & $\begin{array}{l}\text { Extended } \\
\text { model }\end{array}$ \\
\hline \multirow{2}{*}{$\begin{array}{l}\text { Agricultural } \\
\text { growth }\end{array}$} & $-5.095 * *$ & $-13.516 * * *$ & $-9.865 * * *$ & -5.095\# & $-14.325^{* * *}$ \\
\hline & $(-2.13)$ & $(-3.82)$ & $(-3.67)$ & $(-1.55)$ & $(-4.68)$ \\
\hline \multirow{2}{*}{$\begin{array}{l}\text { Non-agricultural } \\
\text { growth }\end{array}$} & $-4.778^{* *}$ & $-10.613 * * *$ & $-7.877 * * *$ & -3.449 & $-8.398 * * *$ \\
\hline & $(-2.41)$ & $(-3.59)$ & $(-3.33)$ & $(-1.17)$ & $(-4.14)$ \\
\hline \multirow[t]{2}{*}{ Urbanisation rate } & $-0.767 * * *$ & -0.301 & $-0.242 *$ & & $-0.332 *$ \\
\hline & $(-5.68)$ & $(-1.32)$ & $(-1.75)$ & & $(-1.90)$ \\
\hline \multirow[t]{2}{*}{ Governance index } & $-20.755^{* * *}$ & $-22.776^{* *}$ & $-11.721 * * *$ & & $-26.627 * * *$ \\
\hline & $(-3.57)$ & $(-2.18)$ & $(-2.60)$ & & $(-2.90)$ \\
\hline \multirow[t]{2}{*}{ Trade openness } & & & & & $-0.092 *$ \\
\hline & & & & & $(-1.85)$ \\
\hline \multirow{2}{*}{$\begin{array}{l}\text { Military in } \\
\text { politics }\end{array}$} & & & & & $5.224 *$ \\
\hline & & & & & $(1.91)$ \\
\hline \multicolumn{6}{|c|}{ Coefficients for instruments omitted for the sake of space } \\
\hline Observations & 369 & 240 & 349 & 372 & 369 \\
\hline $\begin{array}{l}\text { Number of } \\
\text { countries }\end{array}$ & 69 & 39 & 68 & 69 & 69 \\
\hline $\begin{array}{l}\text { Ramsey RESET } \\
\text { test }\end{array}$ & 0.07 & 0.00 & 0.29 & 0.00 & 0.02 \\
\hline $\begin{array}{l}\text { First-stage } \\
\text { F-stat }\end{array}$ & 977.5 & 466.5 & 1237 & 279.6 & 481.9 \\
\hline $\begin{array}{l}\text { H0: AG > NAG, } \\
p \text {-value }\end{array}$ & 0.41 & 0.04 & 0.09 & 0.14 & 0.00 \\
\hline
\end{tabular}

Source Authors' calculations

$A G$ agricultural growth

Notes $*, * *, * * *$ : significant at $10 \%, 5 \%, 1 \%$. ${ }^{\#}$ : marginally insignificant $(p<0.15)$. $t$-statistics in parentheses. Each sector's growth is weighted by the sector's share of value added in total GDP. RESET tests are based on GMM distance

\section{References}

Alderman, H., Haddad, L., Headey, D., \& Smith, L. (2014). Association between economic growth and early childhood nutrition. The Lancet Global Health, 2(9), e500. https://doi.org/10.1016/ S2214-109X1470266-9.

Bazzi, S., \& Clemens, M. A. (2013). Blunt instruments: Avoiding common pitfalls in identifying the causes of economic growth. American Economic Journal: Macroeconomics, 5(2), 152-186.

Bhutta, Z. A., Ahmed, T., Black, R. E., Cousens, S., Dewey, K., Giugliani, E., Haider, B. A., Kirkwood, B., Morris, S. S., Sachdev, H. P. S., Shekar, M. (2008). What works? Interventions for maternal and child undernutrition and survival. The Lancet, 371(9610), 417-440. 
Brainerd, E., \& Menon, N. (2014). Seasonal effects of water quality: The hidden costs of the Green Revolution to infant and child health in India. Journal of Development Economics, 107, 49-64. https://doi.org/10.1016/j.jdeveco.2013.11.004.

Brückner, M. 2013. On the simultaneity problem in the aid and growth debate. Journal of Applied Econometrics, 28(1):126-150.

Brückner, M., \& Lederman, D. (2015). Trade openness and Economic growth: Panel data evidence from Sub-Sahran Africa. Economica, 82, 1302-1323.

Climatic Research Unit, University of East Anglia. http://www.cru.uea.ac.uk/, Dataset, Accessed February 1, 2016.

Collier, P., Dercon, S. (2009). African Agriculture in 50 years: Smallholders in a rapidly changing world? Paper Presented at the 2009 Food and Agriculture Organization Expert Meeting on "How to Feed the World in 2050". ftp://ftp.fao.org/docrep/fao/012/ak983e/ak983e00.pdf.

Dercon, S. (2013). Agriculture and development: revisiting the policy narratives. Agricultural Economics, 44(s1), 183-187. https://doi.org/10.1111/agec.12062.

FAO, WFP and IFAD. (2012). The state of food insecurity in the world 2012. Economic growth is necessary but not sufficient to accelerate reduction of hunger and undernutrition. Rome, FAO.

Harttgen, K., Klasen, S., \& Vollmer, S. (2013). Economic growth and child undernutrition in subSaharan Africa. Population and Development Review, 39, 397-412. https://doi.org/10.1111/j. 1728-4457.2013.00609.x.

Headey, D. (2013). Developmental drivers of nutritional change: A cross-country analysis. World Development, 42, 76-88. https://doi.org/10.1016/j.worlddev.2012.07.002.

Heltberg, R. (2009). Undernutrition, poverty and economic growth. Health Economics, 18, S77S88. https://doi.org/10.1002/hec.1462.

ILO. (2017). Child labour in Africa. http://www.ilo.org/ipec/Regionsandcountries/Africa/lang-en/ index.htm.

Johnston, B., \& Mellor, J. (1961). The role of agricultural in economic development. The American Economic Review, 4, 566-593.

Leroy, J. L., Ruel, M., \& Habicht, J. P. (2013). Critical windows for nutritional interventions against stunting. American Journal of Clinical Nutrition, 98(3), 854-855.

Levine, D. I., \& Rothman, D. (2006). Does trade affect child health? Journal of Health Economics, 25(3), 538-554.

Mary, S. (2018). How much does economic growth really contribute to child stunting reductions? Working Paper, DePaul University.

Mary, S., Saravia-Matus, S., Gomez y Paloma, S. (2018a). Does nutrition-sensitive aid reduce the prevalence of undernourishment? Food Policy, 74, 100-116.

Mary, S., Shaw, K., Gomez y Paloma, S. (2018b). Does the sectoral composition of growth affect child stunting reductions? Development Policy Review (Accepted article).

Mellor, J. (1976). The new economics of growth: A strategy for India and the developing world. Ithaca, NY, USA: Cornell University Press.

Millward, D. J. (2017). Nutrition, infection and stunting: the roles of deficiencies of individual nutrients and foods, and of inflammation, as determinants of reduced linear growth of children. Nutrition Research Reviews, 30, 50-72.

O'Connell, S. A., Smith, C. (2016). Economic growth and child undernutrition. The Lancet Global Health 4, December, Correspondence.

Political Risk Services. (2016). International country risk guide. https://www.prsgroup.com, Dataset. Accessed February 1, 2016.

Prendergast, A. J., \& Humphrey, J. H. (2014). The stunting syndrome in developing countries. Paediatrics and International Child Health, 34(4), 250-264.

Prentice, A. M., Ward, K. A., Goldberg, G. R., Jarjou, L. M., Moore, S. E., \& Fulford, A. J. (2013b). Critical windows for nutritional interventions against stunting. Reply to JL Leroy et al. American Journal of Clinical Nutrition. 
Prentice, A. M., Ward, K. A., Goldberg, G. R., Jarjou, L. M., Moore, S. E., \& Fulford, A. J. (2013a). Critical windows for nutritional interventions against stunting. American Journal of Clinical Nutrition, 97, 911-918.

Ruel, M. T., \& Alderman, H. (2013). The Maternal and Child Nutrition Study Group. 2013. Nutrition-sensitive interventions and programmes: How can they help to accelerate progress in improving maternal and child nutrition? The Lancet, 382(9891), 536-551. http://dx.doi.org/ 10.1016/S0140-67361360843-0.

Smith, L. C., \& Haddad, L. (2015). Reducing child undernutrition: past drivers and priorities for the post-MDG era. World Development, 68, 180-204. https://doi.org/10.1016/j.worlddev.2014. 11.014 .

Stock, J. H., \& Yogo, M. (2005). Testing for weak instruments in Linear IV regression. In J. H. Stock, \& D. W. K. Andrews (Eds.), Identification and inference for econometric models: Essays in Honor of Thomas J. Rothenberg. New York: Cambridge University Press.

UNICEF. (1998). The state of the world's children. New York: United Nations Children's Fund.

Vollmer, S., Harttgen K., Subramanyam, M., Finlay, J., Klasen, S., \& Subramanian, S. V. (2014). Association between economic growth and early childhood undernutrition: evidence from 121 Demographic and health Surveys from 36 low-income and middle-income countries. The Lancet Global Health 2, April. http://dx.doi.org/10.1016/S2214-109X1470025-7.

Webb, P., \& Block, S. (2012). Support for agriculture during economic transformation: Impacts on poverty and undernutrition. Proceedings of the National Academy Sciences, 109(31), 1230912314. https://doi.org/10.1073/pnas.0913334108.

World Bank. (2007). World Development Report 2008: Agriculture for development. World Bank, Washington D.C. https://doi.org/10.1596/978-0-8213-7235-7.

World Bank, World Development Indicators, The World Bank, Washington D.C. http:// data.worldbank.org/data-catalog/world-development-indicators, Dataset, Accessed 1st February 2016.

World Health Organization, Geneva. http://apps.who.int/gho/data/node.main.522, Dataset. Accessed February 1, 2016.

Dr. Sébastien Mary is an instructor in the Department of Economics at the Driehaus College of Business at DePaul University, USA, and a lecturer of economics at the University of Kansas. He completed his Ph.D. at the University of Aberdeen, UK. Previously, he has held positions at the University of Aberdeen and at the European Commission's Joint Research Centre. His research interests include agricultural policy, rural development and food security. His recent work has focused on revisiting the links between agriculture and hunger. He has been particularly interested in the role of economic growth and foreign aid on child nutrition and mortality in developing countries.

Open Access This chapter is licensed under the terms of the Creative Commons Attribution 4.0 International License (http://creativecommons.org/licenses/by/4.0/), which permits use, sharing, adaptation, distribution and reproduction in any medium or format, as long as you give appropriate credit to the original author(s) and the source, provide a link to the Creative Commons license and indicate if changes were made.

The images or other third party material in this chapter are included in the chapter's Creative Commons license, unless indicated otherwise in a credit line to the material. If material is not included in the chapter's Creative Commons license and your intended use is not permitted by statutory regulation or exceeds the permitted use, you will need to obtain permission directly from the copyright holder.

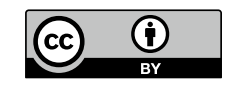

